\title{
Strategy to enhance the therapeutic effect of doxorubicin in human hepatocellular carcinoma by selenocystine, a synergistic agent that regulates the ROS-mediated signaling
}

\author{
Cundong Fan ${ }^{1}$, Wenjie Zheng ${ }^{1}$, Xiaoyan $\mathrm{Fu}^{1}$, Xiaoling $\mathrm{Li}^{1}$, Yum-Shing Wong ${ }^{2}$, \\ Tianfeng Chen ${ }^{1}$ \\ ${ }^{1}$ Department of Chemistry, Jinan University, Guangzhou 510632, China \\ 2 School of Life Sciences and State Key Laboratory of Agrobiotechnology, The Chinese University of Hong Kong, Hong Kong \\ S.A.R., China \\ Correspondence to: Tianfeng Chen, email: tchentf@jnu.edu.cn
}

Keywords: selenocystine; synergism; doxorubicin; apoptosis; reactive oxygen species

Received: January 1, 2014

Accepted: March 24, 2014

Published: March 25, 2014

This is an open-access article distributed under the terms of the Creative Commons Attribution License, which permits unrestricted use, distribution, and reproduction in any medium, provided the original author and source are credited.

\section{ABSTRACT:}

Doxorubicin-based chemotherapy represents one of the most effective ways in combating human cancers. However, its clinical use is limited by severe side effects. Selenocystine $(\mathrm{SeC})$ is a natural available selenoamino acid with novel anticancer efficacy. In this study, we used SeC to sensitize HepG2 human hepatocellular carcinoma (HCC) cells to DOX, and to achieve anticancer synergism in vitro and in vivo. Treatment with DOX dose-dependently reduced HepG2 cell viability through initiating cell apoptosis and strong G2/M phase cell cycle arrest. Mechanistic studies indicated that this sensitization of SeC to DOX was achieved by triggering inactivation of ERK and AKT and DNA damage through reactive oxygen species (ROS) overproduction. Pretreatment with inhibitors of ERK and AKT markedly enhanced combined treatmentinduced cell killing, indicating that combined treatment-induced HCC cell killing with ERK- and AKT-dependent manner. Furthermore, inhibition of ROS effectively attenuated combined treatment-induced DNA damage and inactivation of ERK and AKT. Additionally, xenograft hepatocellular carcinoma growth was also effectively inhibited by combined treatment through induction of cell apoptosis in vivo. Taken together, our results suggest that the strategy to use SeC and DOX in combination could be a highly efficient way to achieve anticancer synergism against HCC.

\section{INTRODUCTION}

Human hepatocellular carcinoma (HCC) is the fifth most frequent neoplasm worldwide and the third leading cause of cancer-related mortality [1-4]. To date, systemic chemotherapeutic treatment is ineffective against HCC cells, due to the resistance to apoptosis and severe sideeffect to normal tissues [5]. Therefore, new therapeutic strategies are urgently needed. Doxorubicin (DOX), an anthracycline antibiotic, is one of the most effective and widely used chemotherapeutic agent for treatment of human various malignancies, including metastatic breast cancer, lymphomas and sarcomas, as well as other human neoplasms $[6,7]$. Nevertheless, the most common adverse effects limiting the clinical use of DOX are cardiotoxicity and even heart failure that carry a poor prognosis and are frequently fatal [6-8]. Increasing studies proved that the proposed mechanisms of anti-malignancy effects of DOX ascribe to intercalation into DNA leading to inhibition of synthesis of macromolecules, generation of reactive oxygen species, DNA binding and DNA cross-linking and DNA damage by inhibition of topoisomerase II, and eventually induce apoptosis or/and cell cycle arrest [7, 9, 10]. Due to drug resistance and the severe side effects, single-agent chemotherapy is no longer appropriate for treating human tumors. Recently, combination (rather than single-agent) chemotherapy has been found to be a superior treatment strategy [1, 11-13]. Hence, much effort has been made to identify chemo-sensitizers, that is, agents that are able to augment efficiency of anticancer drugs and simultaneously overcome multi-drug resistance (MDR) and side effects [14-16]. 
Selenium (Se), as an essential mineral trace element, is of much importance to animals and humans [17]. Much evidences demonstrates that supplement of Se can effectively reduce cancer risk [18-20]. Additionally, recently studies indicated that Se has a potential to increase the efficiency of cancer therapy where in combination with other anticancer drugs [21, 22]. For instance, Li et al reported that selenium can synergizes $\mathrm{MCF}-7$ human breast cancer cells to DOX-induced apoptosis through modulation of phosphorylated AKT and its downstream substrates [21]. However, the apoptotic mechanism induced by Se-compounds remains elusive, especially this synergistic effect of Se combination treatment.

Selenocystine (SeC) is a naturally available selenoamino acid, which exhibits broad-spectrum antiproliferative activity against several human tumor cells through oxidative stress-mediated apoptosis [23].
Despite this potency, $\mathrm{SeC}$ showed less toxic to HK-2 human normal cells, indicating the splendid selectivity of $\mathrm{SeC}$ and predicting the potential application in cancer chemoprevention [23, 24]. Moreover, we just reported that SeC can synergize auranofin-induced apoptosis in MCF-7 human breast cancer cells through triggering ROS-mediated DNA damage by triggering thioredoxin reductase (TrxR) [25]. In this study, we evaluated the ability of SeC to synergize the inhibitory action of DOX in HCC cells, and mechanistic investigation elucidated that $\mathrm{SeC}$ as a potential chemo-sensitizer can dramatically enhances DOX-induced cell killing against HCC cells in vitro and in vivo by triggering ROS-mediated DNA damage. Our study indicates that the strategy to use $\mathrm{SeC}$ and DOX in combination could be a highly efficient way to achieve anticancer synergism.
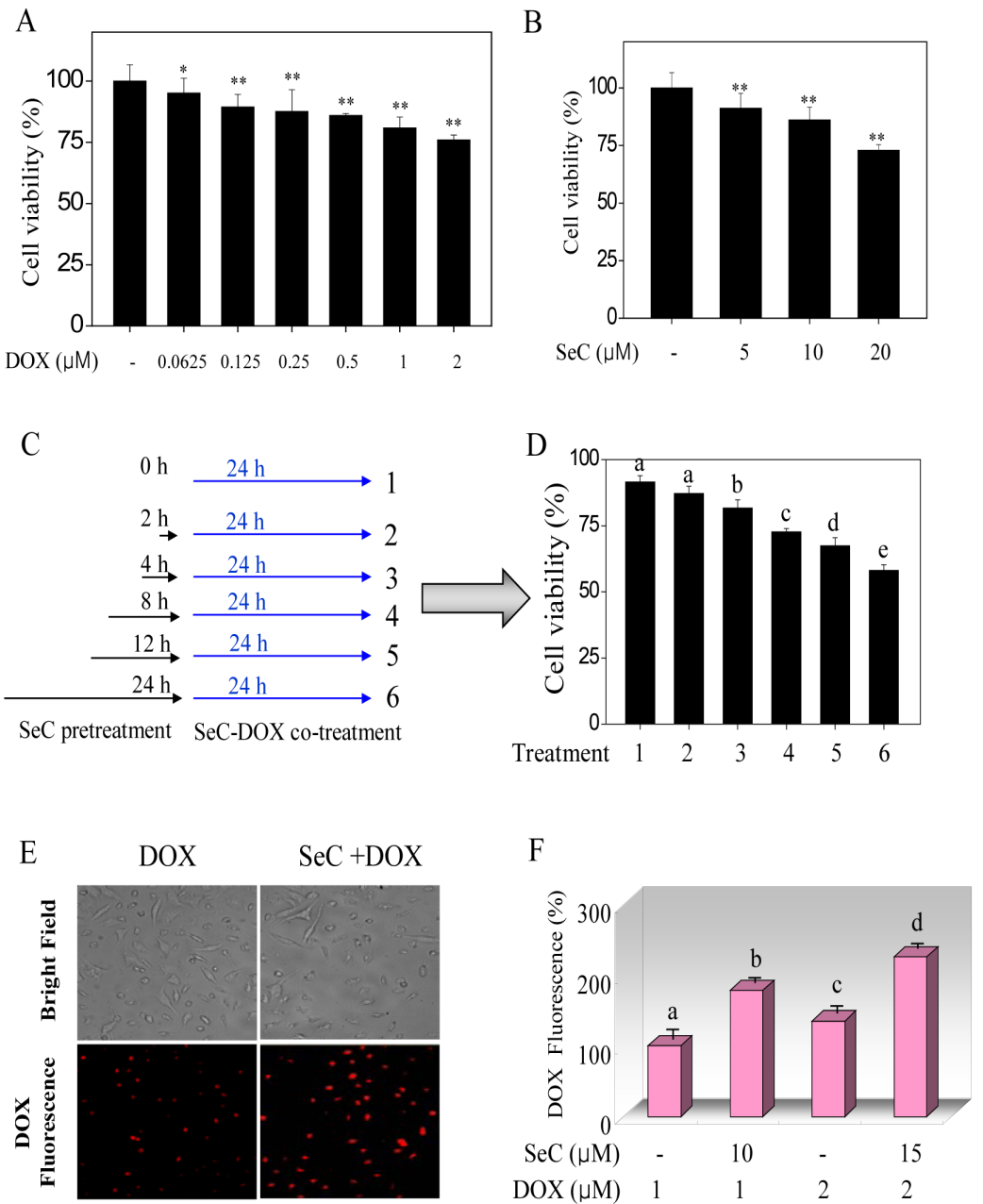

Figure 1: SeC enhances DOX-induced growth inhibition against HepG2 cells through enhanced intracellular uptake of DOX. Cytotoxic effect of DOX (A) and SeC (B) on HepG2 cells. HepG2 cells $\left(2 \times 10^{3}\right.$ cells/well) were seeded in 96-well plate and preincubated for $24 \mathrm{~h}$. After incubation, cells were treated with indicated concentration of DOX for $24 \mathrm{~h}$ or SeC for $48 \mathrm{~h}$. Cell viability was detected by MTT assay. (C, D) Combined treatment enhanced growth inhibition against HepG2 cells induced by SeC and DOX. The cells were pre-treated with $10 \mu \mathrm{M} \mathrm{SeC}(0,2,4,8,12$ and $24 \mathrm{~h})$ and co-incubated with $100 \mathrm{nM}$ DOX for $24 \mathrm{~h}$. Cell viability was determined by MTT assay. Intracellular uptake of DOX was detected by fluorescence microscope (C) and fluorescence micro-plate reader (D). Cells were pre-treated with $\mathrm{SeC} 24 \mathrm{~h}$ and/or DOX for $24 \mathrm{~h}$ and assayed by fluorescence microscope (Magnification, 100 $\times$ ) and fluorescence microplate reader as described in section of methods. Bars with different characters are statistically different at $\mathrm{P}<0.05$ level. 


\section{RESULTS}

\section{SeC enhances DOX-induced HepG2 cell killing by enhancing intracellular DOX accumulation.}

Screening experiments were performed to ascertain the time and dose of $\mathrm{SeC}$ with $\mathrm{DOX}$ for the combined treatment in HepG2 cells. Treatment of HepG2 cells with
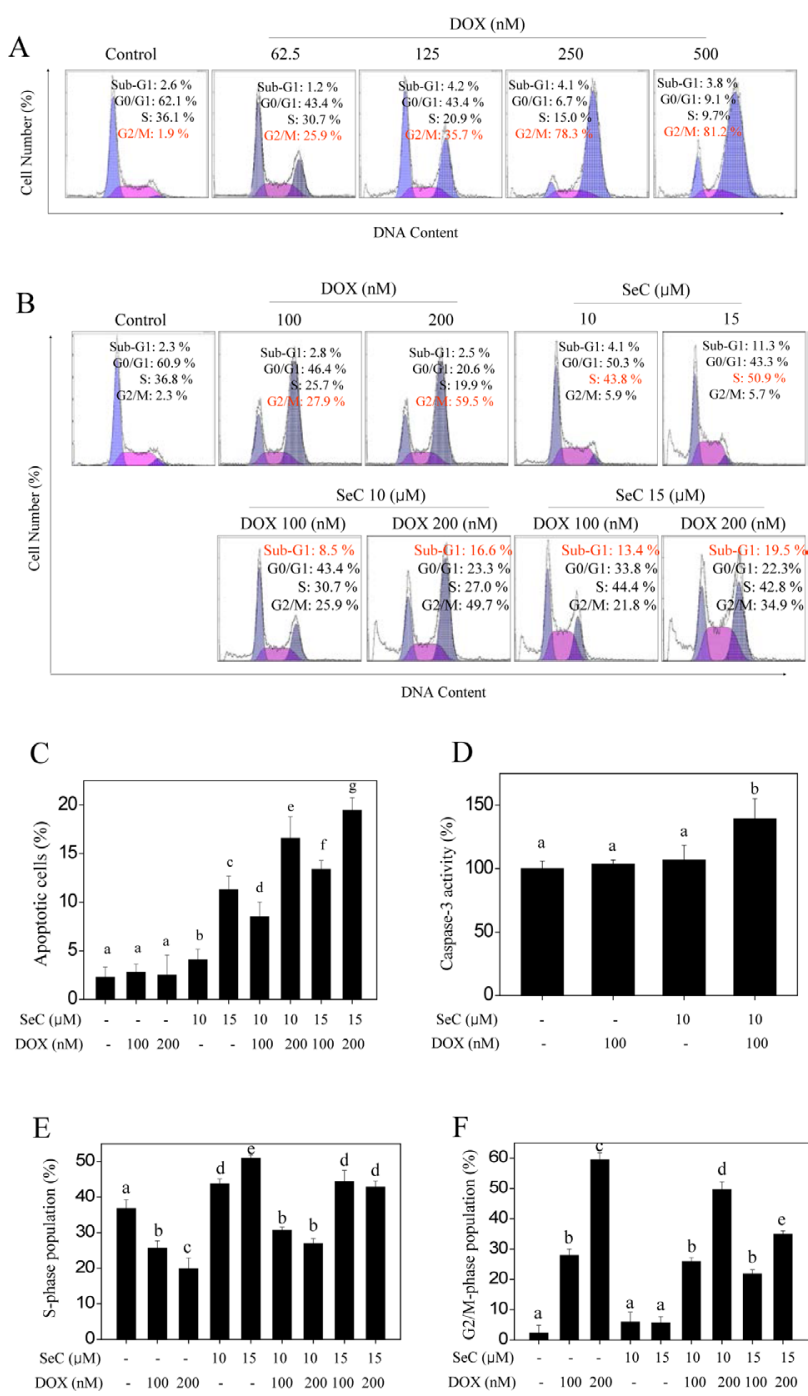

Figure 2: Apoptosis and cell cycle arrest induced by $\mathrm{SeC}$ or/and DOX. A. DOX triggers G2/M cell cycle arrest in HepG2 cells in dose-dependent manner. HepG2 cell were pretreated with $10 \mu \mathrm{M} \mathrm{SeC}$ for $24 \mathrm{~h}$ and co-treated with $100 \mathrm{nM}$ DOX for $24 \mathrm{~h}$.

B. Combined treatment with $\mathrm{SeC}$ and DOX triggers apoptosis and cycle arrest. Cells after treatment were collected and stained with PI solution after fixation by $70 \%$ ethanol. Then cells was analyzed by flow cytometric analysis. Apoptotic cells with hypodiploid DNA content were measured by quantifying the sub-G1 peak. Statistical analysis of apoptotic cell (C) and cell cycle population (E and F). D. Caspase-3 activity. Cell after treatment were lysed and the cell proteins was used to determine caspase-3 activity using specific fluorescence substrates.
$\mathrm{SeC}$ for $48 \mathrm{~h}$ or with DOX for $24 \mathrm{~h}$ alone inhibited the cell growth in dose-dependent manner (Fig. 1A and B). Interestingly, combined treatments of the cells with $\mathrm{SeC}$ and DOX significantly enhanced cell growth inhibition (Fig. 1C, D and Fig. S1A). For instance, treatment of HepG2 cells with $10 \mu \mathrm{M} \mathrm{SeC}$ for $48 \mathrm{~h}$ or with $100 \mathrm{nM}$ DOX for $24 \mathrm{~h}$ reduced cell viability by $13.8 \%$ and 7.2 $\%$, respectively. Nevertheless, combination of $10 \mu \mathrm{M}$ $\mathrm{SeC}$ (pretreatment for $24 \mathrm{~h}$ ) with $100 \mathrm{nM}$ DOX (cotreatment for another $24 \mathrm{~h}$ ) significantly decreased the cell viability by $38.8 \%$ (Fig. S1A), implying that $\mathrm{SeC}$ effectively enhanced DOX-induced growth inhibition against HepG2 cells. Cell morphological change further confirmed the growth suppressive effect on HepG2 cells (Fig. S1B). Additionally, the interaction mode between $\mathrm{SeC}$ and DOX was examined by interaction index $(\gamma)$ by isobologram analysis. Preliminary studies found that the $\mathrm{IC}_{50}$ value of SeC and DOX alone is $46.4 \mu \mathrm{M}$ and $2.9 \mu \mathrm{M}$, respectively. Moreover, treatment of cells with $20 \mu \mathrm{M}$ $\mathrm{SeC}$ in combination with $0.5 \mu \mathrm{M}$ DOX displayed $50 \%$ cell killing. Therefore, the interaction index was $\gamma=0.6<1$, meaning that the combined effects between $\mathrm{SeC}$ and DOX was strongly synergistic.

DOX is an auto-fluorescent agent, allowing the visualization of its intracellular presence by fluorescence microscopy. To investigate the synergetic effect of $\mathrm{SeC}$ and DOX, intracellular accumulation of DOX was examined by detecting the intracellular fluorescence of DOX in HepG2 cells after treatment with $\mathrm{SeC}$ or /and DOX. As expected, HepG2 cells after treatment with $100 \mathrm{nM}$ DOX alone showed weak red fluorescence in the nuclei (Fig. 1E). However, the intracellular fluorescence of DOX in HepG2 cells after pretreatment with $10 \mu \mathrm{M} \mathrm{SeC}$ was remarkable higher than that of DOX treatment alone (Fig. $1 \mathrm{E}$ and F). The enhanced fluorescence intensity of DOX further confirmed this conclusion that, $\mathrm{SeC}$ pretreatment enhanced DOX uptake in HepG2 cells (Fig. 1 F). Taken together, these results indicate that $\mathrm{SeC}$ enhances DOXinduced cell killing ability through enhancing its cellular uptake.

SeC and DOX induce cell apoptosis and cell cycle arrest.

To determine the cause of combined treatmentinduced cell death is apoptosis or/and cell cycle arrest, PI staining detected by flow cytometry was employed to evaluate combined treatment-induced cell death. HepG2 cells treated with indicated concentration of DOX initiated an apparent G2/M-phase cell cycle arrest with a dose-dependent manner, no obvious cell apoptosis was observed (Fig. 2A). Exposure of HepG2 cells to indicated concentration of $\mathrm{SeC}$ caused a marked cell apoptosis and S-phase cell cycle arrest (Fig. 2B). However, combined treatment of HepG2 cells with $\mathrm{SeC}(10$ and $15 \mu \mathrm{M})$ 
and DOX (100 and $200 \mathrm{nM}$ ) resulted in a enhanced cell apoptosis compared with that of $\mathrm{SeC}$ and $\mathrm{DOX}$ alone, as reflected by the increase in sub-G1 peaks (Fig. 2B, C). Furthermore, DOX-induced G2/M-phase cell cycle arrest was blocked at S-phase by SeC (Fig. 2E, F). Enhanced cell apoptosis induced by combined treatment was confirmed by caspase- 3 activity using substrate Ac-DEVD-AMC. As shown in Fig. 2D, pretreatment of HepG2 cells with SeC significantly enhanced the DOX-induced activation of caspase-3 from $103.6 \%$ (DOX), $106.8 \%$ (SeC) to $139.5 \%$ (combination). Taken together, these results suggest that $\mathrm{SeC}$ can act as an enhancer to sensitizes DOX-induced HepG2 cell killing by induction of apoptosis and cell cycle arrest.

\section{ERK and AKT pathways contribute to the combined treatment-induced growth inhibition against HepG2 cells.}

Accumulated evidences indicate that $\mathrm{HCC}$ cell activation by different factors is known to increase MEK/ERK and PI3K/AKT signaling [26]. To examine whether MEK/ERK and PI3K/AKT signaling involved in combined treatment-induced HCC cell growth inhibition, western blotting method was employed to detect ERK and AKT expression in vitro using phosphorylated antibodies. As shown in Fig. 3A, treatment of HepG2 cells with $\mathrm{SeC}$ and DOX alone both slightly inhibited the phosphorylation of ERK (Thr 202/Tyr 204) and AKT (Ser 473). However, pretreatment of HepG2 cells with SeC significantly enhanced DOX-induced inactivation of ERK and AKT (Fig. 3A). To further evaluate the role of $\mathrm{SeC}$, a time course effect of $\mathrm{SeC}$ on ERK and AKT expression was assayed. As expected, exposure of HepG2 cells to $10 \mu \mathrm{M} \mathrm{SeC}$ for indicated time resulted in a notable down-regulation of ERK and AKT expression in timedependent manner (Fig. 3C), indicating that SeC can act as an inhibitor of ERK and AKT to synergize DOX-induced HepG2 cell growth inhibition. Based on the importance of ERK and AKT, two inhibitors of ERK (U0126) and AKT (LY294002) were used to determine combined treatmentinduced HepG2 cell killing. The MTT assay suggested that pretreatment with inhibitors only for $1 \mathrm{~h}$ obviously enhanced combined treatment-induced cell growth inhibition against HepG2 cells (Fig. 3B). Pretreatment
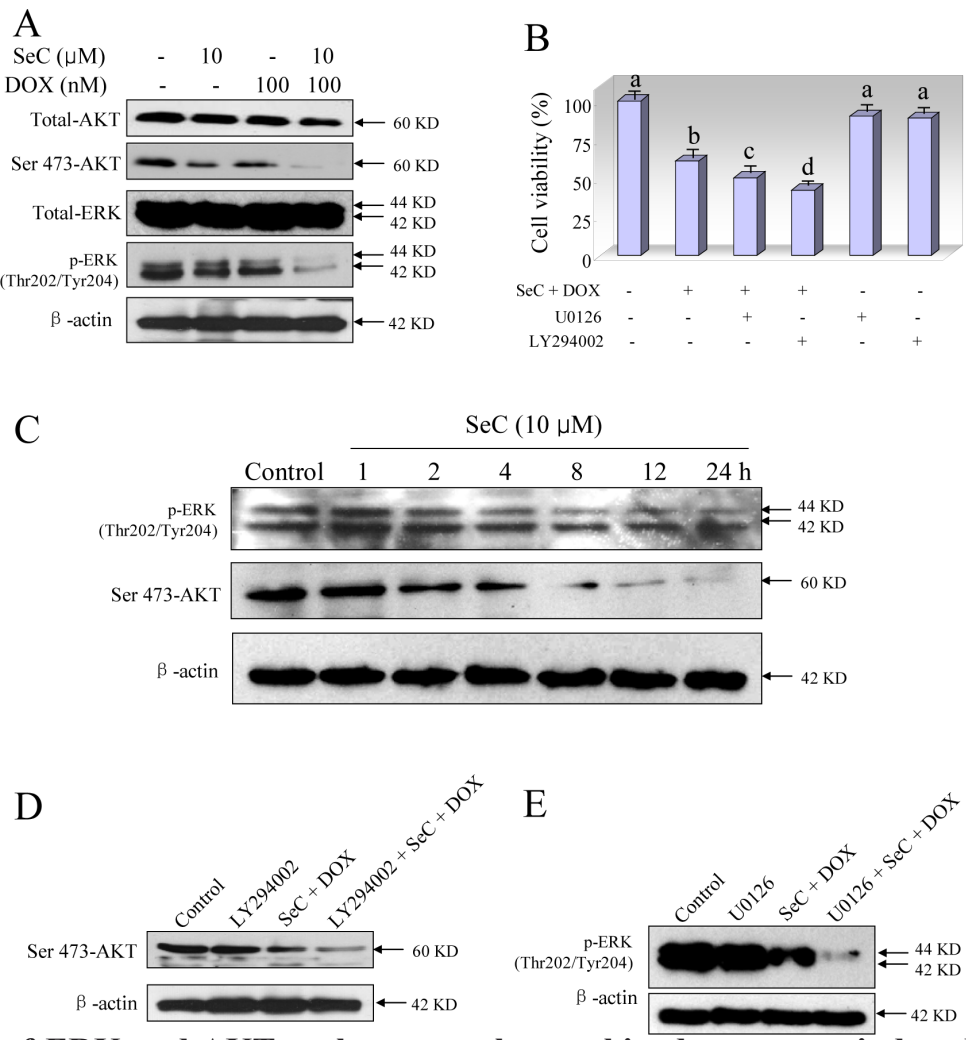

Figure 3: Contribution of ERK and AKT pathways to the combined treatment-induced growth inhibition against HepG2 cells. A. SeC synergizes DOX-induced inactivation of ERK and AKT. Protection expression was detected by western blotting method. Briefly, HepG2 cell were pre-treated with $10 \mu \mathrm{M} \mathrm{SeC}$ for $24 \mathrm{~h}$ and co-treated with $100 \mathrm{nM}$ DOX for $24 \mathrm{~h}$. Then cells were lysed and total protein were separated by SDS-PAGE and immunoblotted with specific primary antibodies. Equal loading was affirmed by stripping immunoblots and reprobing for $\beta$-actin. B. Inhibitors of ERK (U0126) and AKT (LY294002) enhance combined treatment-induced growth inhibition against HepG2 cells. Cells were pretreated with $10 \mu \mathrm{M}$ U0126 or $10 \mu \mathrm{M}$ LY294002 for $1 \mathrm{~h}$ before combined treatment with SeC and DOX. Cell viability was detected by MTT assay. C. Time-dependent effects of SeC on expression of p-AKT and p-ERK in HepG2 cells. D. Inhibitors of AKT (LY294002) enhance combined treatment-induced inactivation of AKT. E. Inhibitors of ERK (U0126) enhance combined treatment-induced inactivation of ERK. 
of the cells with inhibitors of AKT (LY294002) and ERK (U0126) for $1 \mathrm{~h}$ effectively enhanced the combined treatment-induced dephosphorylation of ERK and AKT (Fig. $3 \mathrm{D}$ and E). These results all indicated that combined treatment reduced HepG2 cell viability with ERK- and AKT-dependent manner. SeC as inhibitors of ERK and AKT signaling synergizes DOX-induced growth inhibition against HepG2 cells.

\section{SeC enhances DOX-induced DNA damage through ROS overproduction.}

DOX is reported to produce ROS as a part of its anticancer mechanisms [9]. Our previously proved that $\mathrm{SeC}$ can induced several human cancer cells apoptosis through ROS-mediated oxidative damage [23]. Hence, we asked whether $\mathrm{SeC}$ could enhance the ROS accumulation induced by DOX. As expected, SeC treatment alone caused apparent ROS overproduction in time-dependent manner as convinced by the enhanced green fluorescence intensity (Fig. S2). SeC pretreatment significantly enhanced DOX-induced ROS generation in timedependent manner, and the ROS generation was observed as early as $5 \mathrm{~min}$ (Fig. 4A), indicating the significance

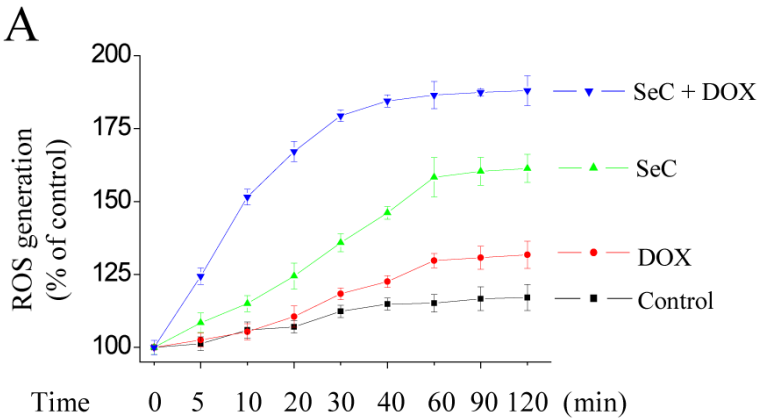

$\mathrm{C}$

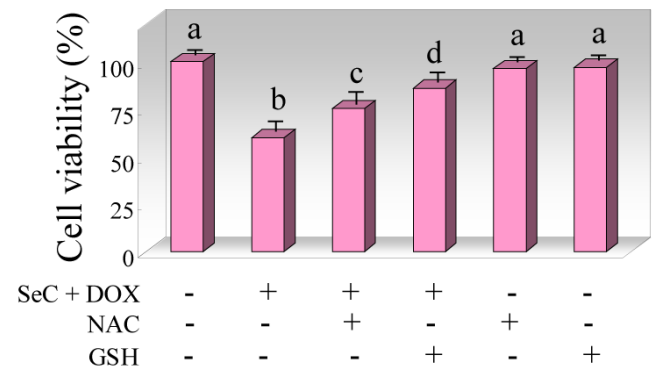

of ROS as early event in regulating cell apoptosis or/and cell cycle arrest. Abundant intracellular ROS may cause DNA damage and activate down-streamed signaling pathway. Therefore, combined treatment-induced DNA damage was also detected using two DNA damage markers, phosphorylated p53 (Ser 15) and phosphorylated histone (Ser 139). As shown in Fig. 4B, treatment with $\mathrm{SeC}$ and DOX alone both triggered DNA damage, as convinced the up-regulated phosphorylated level of p53 and histone. However, combined treatment caused more severe DNA damage (Fig. 4B). Moreover, the combined treatment-induced DNA damage was further confirmed by DAPI staining. As shown in Fig. S3, pretreatment of HepG2 cells with SeC significantly enhanced DOXinduced chromatin condensation. Synergistic induction of DNA fragmentation by $\mathrm{SeC}$ and $\mathrm{DOX}$ was further confirmed by PI flow cytometric analysis, as evidenced by the increase of Sub-G1 peak (Fig. 2). We speculated the possibility that overproduced ROS induced by $\mathrm{SeC}$ transfered into nucleus to enhance DOX-mediated DNA damage. For further evaluation of ROS, two thiolreducing antioxidant, glutathione (GSH) and N-acetylL-cysteine (NAC), were introduced to examine the role of intracellular ROS in combined treatment-induced cell death. As shown in Fig. 4C, pretreatment with 5 mM NAC
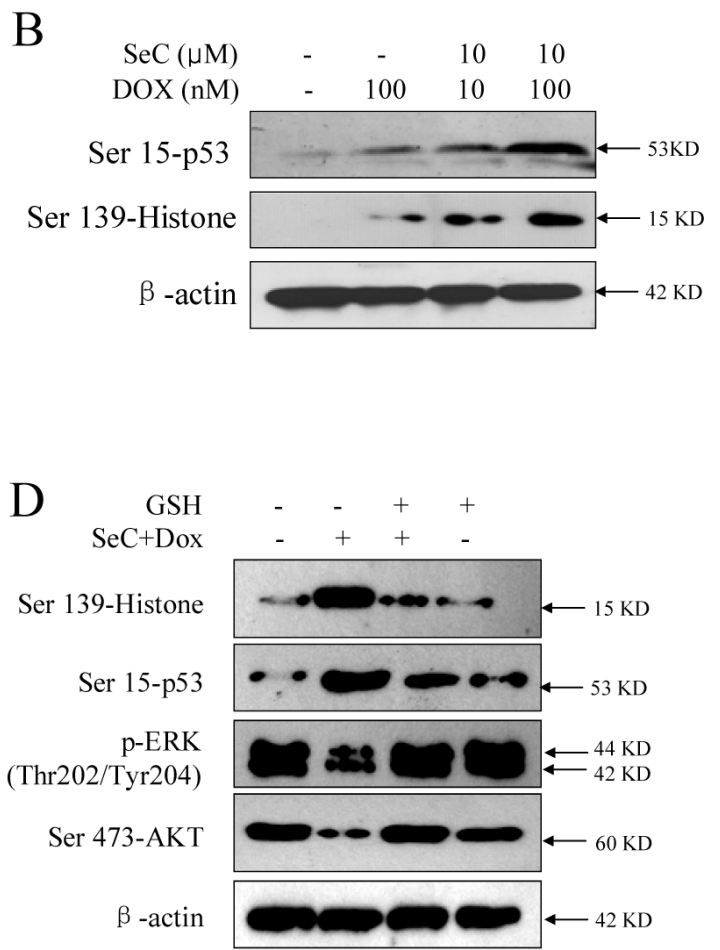

Figure 4: SeC synergizes DOX-induced DNA damage through ROS overproduction. A. SeC enhances DOX-induced ROS accumulation. HepG2 cells (105 cells/well) were pretreated with $10 \mu \mathrm{M} \mathrm{SeC}$ for $1 \mathrm{~h}$ and co-incubated with $100 \mathrm{nM}$ DOX for another $1 \mathrm{~h}$, and then the time-course of ROS generation was measured by a fluorescence probe, DCFH-DA. B. SeC enhances DOX-induced phosphorylation of p53 and histone. HepG2 cell were pre-treated with $10 \mu \mathrm{M} \mathrm{SeC}$ for $24 \mathrm{~h}$ and co-treated with $100 \mathrm{nM}$ DOX for 24 $\mathrm{h}$. Then cells were lysed and the protein expression was examined by western blotting methods. C. Inhibition of ROS elevates the cell viability induced by combined treatment. Cells were pre-treated with $5 \mathrm{mM} \mathrm{GSH}$ or NAC for $2 \mathrm{~h}$ before combination treatment. Trypan blue staining was employed to quantify cell death. D. GSH supplement attenuates DOX-induced DNA damage and inactivation of ERK and AKT. Protein expression was detected by western blotting method. 
A
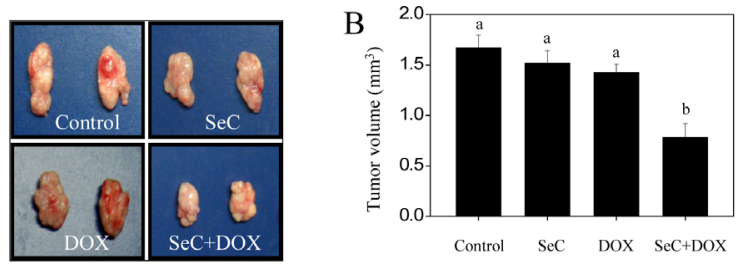

$\mathrm{C}$

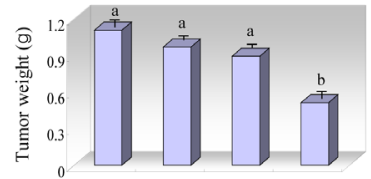

D

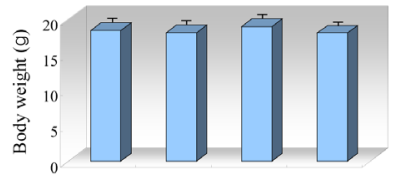

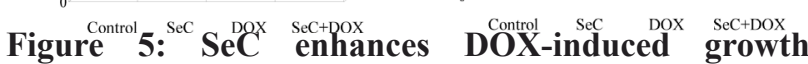
inhibition of tumor xenografts. Combined treatment inhibits tumor volume (A, B) and tumor weight (C) of HepG2 human hepatoma carcinoma xenografts in nude mice, but not affect body weight (D) of mice.

or GSH for $2 \mathrm{~h}$ effectively prevented HepG2 cells from combined treatment-induced cell growth inhibition. For instance, combination treatment of $\mathrm{SeC}(10 \mu \mathrm{M})$ with DOX $(100 \mathrm{nM})$ decreased the cell viability to $59.9 \%$. However, pretreatment of cells with $5 \mathrm{mM}$ NAC or GSH

A
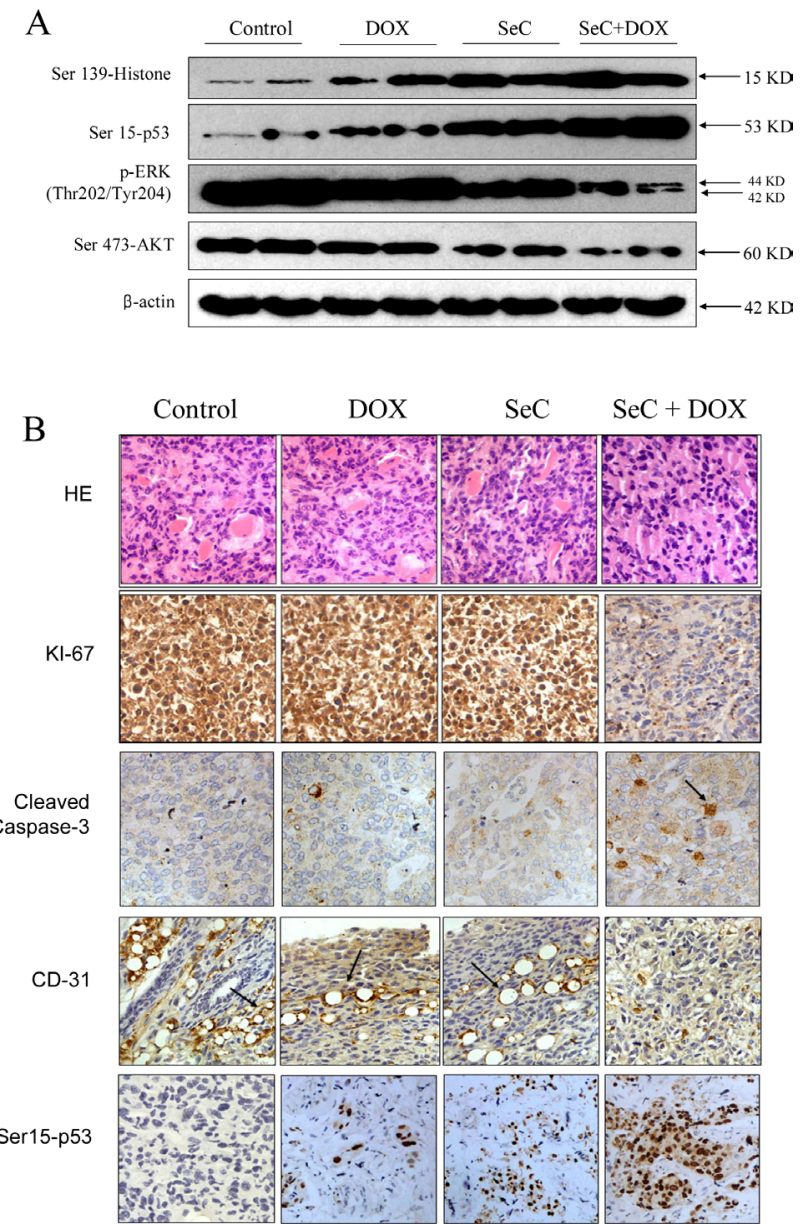

Figure 6: Combined treatment triggers DNA damage and inactivation of ERK and AKT in vivo. A. Proteins expression detected by western blotting in vivo. B. Staining of tumor xenografts by HE and IHC method. reversed the combined treatment-induced reduction of cell viability to $75.6 \%$ and $86.2 \%$, respectively (Fig. 4C). In addition, GSH supplement effectively suppressed combined treatment-induced DNA damage and attenuated the inactivation of ERK and AKT (Fig. 4D), revealing the importance of ROS in DNA damage and regulation of ERK and AKT pathways.

\section{SeC amplifies the therapeutic effect of DOX in vivo.}

To evaluate the synergetic effect of $\mathrm{SeC}$ and DOX in vivo, immuno-deficient nude mice bearing $\mathrm{HCC}$ tumor xenografts were employed to investigate the therapeutic effect of $\mathrm{SeC}$ in combination with DOX. As expected, after 14 days' administration, treatment of $\mathrm{SeC}$ and DOX alone both slightly inhibited HCC tumor xenografts growth. However, HCC tumor xenografts growth in rude mice was more effectively inhibited by combined treatment with $\mathrm{SeC}$ and DOX in vivo. For instance, combined treatment with $\mathrm{SeC}$ and DOX significantly inhibited the tumor volume (Fig. 5A, B) and tumor weight (Fig. 5C), but not affected body weight of mice (Fig. 5D). The in vivo mechanistic studies revealed that combined treatment inhibited tumor xenografts by induction of AKT and ERK inactivation and triggering DNA damage (Fig. 6 A), which were consistent with the results in vitro. Furthermore, several cell markers using IHC methods further confirmed that combined treatment triggered cell apoptosis (cleaved caspase-3 staining), inhibited angiopoiesis (CD31 staining), activated p53 phosphorylation (Ser15-p53 staining) and inhibited tumor xenografts cell proliferation (Ki67 staining) (Fig. 6B). Statistic analysis of the protein expression levels by Leica QW550 software further confirmed this anti-tumor effect in vivo (Fig. S4). Taken together, these results all indicated that $\mathrm{SeC}$ synergizes the therapeutic effect of DOX in vivo by DNA damagemediated p53 phosphorylation.

\section{DISCUSSION}

In the present study, we validated for the first time that $\mathrm{SeC}$ synergizes DOX-mediated HepG2 cell killing in vitro and in vivo and the possible mechanisms. The results show that DOX inhibited the growth of HepG2 cells by induction of G2/M cell cycle arrest, and $\mathrm{SeC}$ induced growth inhibition against HepG2 cell through S-phase arrest and cell apoptosis. However, combined treatment with DOX and $\mathrm{SeC}$ significantly inhibited the growth of HepG2 cells by dual-cell cycle arrest and enhanced cell apoptosis. Inhibition of HepG2 cells induced by combined treatment was associated with increased ROS generation, DNA damage, and inactivation of ERK and AKT pathway.

DOX as one of the most effective chemotherapeutic agent was widely used for treating human various 
malignancies $[6-8,20]$. Nevertheless, the side effects, especially the severe cardiotoxicity, badly limited its clinical usage. In the present study, we used $\mathrm{SeC}$, a low cytotoxic agent, to synergize the therapeutic effect of DOX, and the result suggested that the combined treatment effectively induced the HepG2 cell killing. Meanwhile, the combined strategy reduces the effective dosage of DOX (only $100 \mathrm{nM}$ ), but enhance the pharmaceutical effect of DOX, which has the potential to minimize/reverse the side effects and multi-drug resistance (MDR) of DOX with promising application in clinic.

Induction of cell apoptosis or/and cell cycle arrest by chemo-preventive and chemotherapeutic agents in cancer cells is an effective strategy to halt tumor growth [27]. The tumor suppressor p53 is a cell cycle checkpoint protein that contributes to the preservation of genetic stability by mediating either cell cycle arrest or apoptosis in response to DNA damage $[28,29]$. The major molecular sensors, including ATM, ATR, and DNA-PK, can be recruited in response to DNA damage, accompanied by the activation of p53 and downstream pathway [3032]. Finally, activated p53 can cause cell cycle arrest or apoptosis to repair/eliminate the damaged cells [33-37]. In the present study, treatment with $\mathrm{DOX}$ and $\mathrm{SeC}$ alone both triggered the phosphorylation of p53 and histone, indicating that DOX and $\mathrm{SeC}$ both induced DNA damage. Combined treatment resulted in enhanced DNA damage, as convinced by increased expression of p53 and histone. Activation of p53 in response to DNA damage finally induced apoptosis and cell cycle arrest in HepG2 cells.

Recent studies found that the Ras/Raf/MAPK and $\mathrm{PI} 3 \mathrm{~K} / \mathrm{AKT} / \mathrm{mTOR}$ are two activated pathways in HCC cells $[26,32,38-40]$. The PI3K/AKT/mTOR signaling pathway plays a pivotal role in HCC and is activated in 30$50 \%$ of HCC cases [26]. Therefore, searching for effective inhibitors targeting these signaling pathway or their components represents a promising therapeutic strategy recently. In this study, we showed that the combined treatment with $\mathrm{SeC}$ and DOX notably decreased ERK and AKT phosphorylation in cancer cells. Furthermore, pretreatment of the cells with inhibitor of ERK and AKT significantly enhanced the combined treatment-induced cell killing, indicating that ERK and AKT pathway both contributed to combined treatment-induced growth inhibition against HepG2 cells. The results indicated that $\mathrm{SeC}$ as potential inhibitors of ERK and AKT showed promising application in treating human hepatocellular carcinoma.

Human tumor cell killing by chemotherapy agents was usually ascribed to the accumulation of intracellular ROS [41]. Overproduction of intracellular ROS may attack cellular membrane lipids, proteins, DNA and cause oxidative injury, and finally result in reduction of cell cycle arrest or/and cell apoptosis to repair or eliminate the damaged cells [42]. DOX is known to produce ROS as a part of its anticancer mechanisms [9]. Our previous studies found that $\mathrm{SeC}$ could induce several human cancer cell apoptosis by induction of ROS generation [23]. Consistent with expected results, we confirm that DOX and $\mathrm{SeC}$ treatment alone both caused significant ROS accumulation. Although ROS generation was greater in $\mathrm{SeC}$-treated cells, combination of DOX with $\mathrm{SeC}$ further enhanced ROS overproduction.

In view of ROS production, we performed the western blotting method to assess DNA damage using specific phosphorylated antibody, Ser 15-p53 and Ser 139-histone, both DNA damage markers. The results showed that $\mathrm{SeC}$ and DOX pretreatment alone both slightly caused DNA damage in HepG2 cells, as convinced by the up-regulation of Ser 15-p53 and Ser 139-histone. Although DNA damage level was higher in SeC-treated cells, combination treatment with $\mathrm{DOX}$ and $\mathrm{SeC}$ resulted in severer DNA damage in HepG2 cells. However, blocking of ROS production with

ROS scavengers, GSH and NAC, both thiolinducing antioxidants, effectively prevented HepG2 cells from combined treatment-mediated cell killing. Moreover, elimination of ROS by GSH also significantly attenuated phosphorylation of histone and inactivation of ERK and AKT, indicating that ROS act as a early mediator in regulating DNA damage and ERK and AKT pathway. These results provided a possibility that, $\mathrm{SeC}$ inside the cells may oxidize intracellular thiol-containing antioxidant agents. Addition of GSH and NAC not only eliminated ROS, but also replenished intracellular stores of endogenous thiol-containing antioxidants. Our previous studies have already confirmed the conclusion that, ROS as upstream mediator can regulation the phosphorylation of ERK and AKT. Meanwhile, addition of GSH effectively inhibited ROS generation and suppressed the dephosphorylation of ERK and AKT [34]. Taken together, our results suggest that ROS overproduction lead to the induction of DNA damage, and inactivation of ERK and AKT, leading to the activation of caspase- 3 to induce apoptosis and cell cycle arrest.

In summary, we combined $\mathrm{DOX}$ with $\mathrm{SeC}$ to enhance HepG2 cell killing by induction of apoptosis and cell cycle arrest through ROS-mediated DNA damage. We also demonstrated the synergistic effect of DOX/ $\mathrm{SeC}$ combination on suppression of tumor growth in vivo using a xenograft tumor model. Our results suggest that combining low dose of DOX with suboptimal dose of $\mathrm{SeC}$ can serve as a potential combination therapy for treatment of human hepatocellular carcinoma with the potential to minimize/eliminate the side effects associated with high doses of DOX. 


\section{MATERIALS AND METHODS}

\section{Reagents.}

Selenocystine, doxorubicin, propidium iodide [1], 2',7'-dichlorofluorescein diacetate (DCF-DA), 3-[4,5-dimethyl-thiazol-2-yl]-2,5-diphenyltetrazolium bromide (MTT), bicinchoninic acid (BCA) kit for protein determination were purchased from Sigma. Dulbecco's modified Eagle's medium (DMEM), fetal bovine serum (FBS) and the antibiotic mixture (penicillin-streptomycin) were purchased from Invitrogen (Carlsbad, CA). Caspase-3 substrate (Ac-DEVD-AMC) were purchased from

Calbiochem. U0126 and LY294002 were obtained from Calbiochem (San Diego, CA). All of the antibodies used in this study were purchased from Cell Signaling Technology (Beverly, MA). All of the solvents used were of high-performance liquid

chromatography (HPLC) grade. The water used for all experiments was supplied by Milli-Q water purification system from Millipore.

\section{Cell culture.}

HepG2 hepatocellular carcinoma cell line was obtained from American Type Culture Collection (ATCC, Manassas, VA) and maintained in DMEM medium supplemented with fetal bovine serum $(10 \%)$, penicillin $(100$ units $/ \mathrm{ml})$ and streptomycin $(50$ units $/ \mathrm{ml})$ at $37^{\circ} \mathrm{C}$ in a humidified incubator with $5 \% \mathrm{CO}_{2}$ atmosphere.

\section{Cell viability.}

Briefly, HepG2 cells $\left(2 \times 10^{3}\right.$ cells/well $)$ seeded $96-$ well micro-plates were pre-treated with $10 \mu \mathrm{M} \mathrm{SeC}$ for 24 $\mathrm{h}$ and co-incubated with $100 \mathrm{nM}$ DOX for another $24 \mathrm{~h}$. After incubation, cell viability was detected by MTT assay as previously reported [24].

\section{Intracellular uptake of DOX.}

The intracellular uptake of DOX was visualized by fluorescence microscopy and quantified by fluorescence micro-plate reader. Briefly, HepG2 cells $\left(1 \times 10^{5}\right)$ were seeded in 2-cm culture dish and pre-incubated for $24 \mathrm{~h}$. After incubation, cells were pre-treated with $10 \mu \mathrm{M} \mathrm{SeC}$ for $24 \mathrm{~h}$ in the presence or absence of $1 \mu \mathrm{M}$ DOX for another $24 \mathrm{~h}$. After treatment, the cells were washed with PBS for 3 times and the intracellular uptake of DOX was detected by fluorescence microscopy (Magnification, $100 \times$ ). In addition, The intracellular uptake of DOX was quantified by fluorescence micro-plate reader. Briefly, cells were seeded in 96-well micro-plate $\left(2 \times 10^{3}\right.$ cells $/$ well) and treated with $\mathrm{SeC}(10 \mu \mathrm{M})$ or/and DOX (1 $\mu \mathrm{M})$. After treatment, cells were washed with PBS for 3 times and the intracellular uptake of DOX was quantified by fluorescence micro-plate reader with the excitation wavelength and emission wavelength at $485 \mathrm{~nm}$ and 585 $\mathrm{nm}$, respectively. The data was expressed as \% of DOXtreated group $(100 \%)$.

\section{Cell apoptosis and cell cycle distribution.}

Briefly, cells after treatment with $\mathrm{SeC}$ or/and DOX were harvested by centrifugation and washed with PBS. Cells were stained with PI after fixation with $70 \%$ ethanol at $-20^{\circ} \mathrm{C}$ overnight. Then the cell apoptosis and the cell cycle distribution was analyzed by flow cytometric analysis as previously described [24].

\section{Determination of caspase- 3 activity.}

Total protein in HepG2 cells exposed to $\mathrm{SeC}$ or/and DOX was extracted and the protein concentration was quantified by BCA kit. Then the activity of caspase- 3 was detected as previously described [24].

\section{Intracellular ROS accumulation.}

Intracellular ROS accumulation was detected by DCF fluorescence assay. Briefly, HepG2 cells $\left(1 \times 10^{6}\right.$ cells/ $\mathrm{ml})$ in PBS were incubated with $10 \mu \mathrm{M}$ DCFH-DA at $37^{\circ} \mathrm{C}$ for $45 \mathrm{~min}$. Then the cell were washed and the labelled cells were placed in 96-well plate $(100 \mu \mathrm{l} /$ well $)$ and incubated with $10 \mu \mathrm{M} \mathrm{SeC}$ for $1 \mathrm{~h}$. After then, the cells were co-incubated with $100 \mathrm{nM}$ DOX for another $1 \mathrm{~h}$. The intracellular ROS level was determined as previously described [23].

\section{Western blot analysis.}

The total cellular proteins in HepG2 cells exposed to $\mathrm{SeC}$ and/or DOX were extracted and quantified using BCA kit according to the manufacturer's protocols. Then the proteins expression in $\mathrm{HepG} 2$ cells after treatment were investigated by western blotting method as previously described [25].

\section{In vivo study.}

Male nude mice were used to evaluate the in vivo therapeutic effect of $\mathrm{SeC}$ or/and DOX. Briefly, about $1 \times 10^{6} \mathrm{HepG} 2$ cells in $100 \mu \mathrm{L}$ serum-free medium were subcutaneously injected into the right oxter of mice. When average tumor volume reached about $50 \mathrm{~mm}^{3}$ 
after 1 week, mice were randomly divided into four groups (8 mice/group): Group 1 for PBS as control; Group 2 for $5 \mathrm{mg} / \mathrm{kg} \mathrm{SeC}$; Group 3 for $2 \mathrm{mg} / \mathrm{kg} \mathrm{DOX}$; Group 4 for $5 \mathrm{mg} / \mathrm{kg} \mathrm{SeC}+2 \mathrm{mg} / \mathrm{kg}$ DOX. Drugs were injected every other day, caudal vein, from the first day until the fourteenth day ( 7 times). At the termination of the experiments, tumors were harvested, photographed and weighed. Tumor dimensions were measured with calipers and the volume was calculated using the formula: volume $=1 \times \mathrm{w}^{2} / 2$, with 1 being the maximal length and $\mathrm{w}$ being the width. A portion of the tumors from control and treated animals was used for preparation of tumor lysate used in further analysis. Another portion of tumors were removed, fixed in 10\% buffered formalin, embedded with paraffin and sectioned. The $4-\mu \mathrm{M}$ sections were stained with hematoxylin and eosin staining (HE) for histological observation. Protein expression in sections was examined by immunohistochemical (IHC) methods. All animal experiments were approved by the Animal Experimentation Ethics Committee.

\section{Statistical analysis.}

Experiments were carried out at least in triplicate and repeated three times. All data were expressed as mean \pm S.D. Statistical analysis was performed using SPSS statistical package (SPSS 13.0 for Windows; SPSS, Inc. Chicago, IL). The difference between two groups was analyzed by two-tailed Student's t-test. The difference between three or more groups was analyzed by one-way analysis of variance multiple comparisons. Differences with $P<0.05\left(^{*}\right)$ or $P<0.01\left(^{* *}\right.$ ) was considered statistically significant. Bars with different characters are statistically different at $P<0.05$ level. The interaction mode between $\mathrm{SeC}$ and Dox was analyzed by the interaction index which is based on "isobologram analysis" $[34,43]$. The index, denoted by $\gamma$, is defined by the isobolar relation: $\mathrm{a} / \mathrm{A}+$ $\mathrm{b} / \mathrm{B}=\gamma$, where $\mathrm{A}$ and $\mathrm{B}$ are the doses of SeC and DOX used, which give $50 \%$ cell killing, and a and $\mathrm{b}$ are the combination doses that produce the same activity. The quantities in equation are obtained from the dose response curves of drugs A, B, and the combined treatments. If $\gamma=1$, the interaction is additive; if $\gamma<1$, it is synergistic; if $\gamma>1$, it is antagonistic.

\section{ACKNOWLEDGEMENTS}

This work was supported by National High Technology Research and Development Program of China (863 Program, SS2014AA020538), Science Foundation for Distinguished Young Scholars of Guangdong Province, Natural Science Foundation of China and Guangdong Province, Program for New Century Excellent Talents in University, YangFan Innovative \& Entepreneurial Research Team Project, Research Fund for the Doctoral
Program of Higher Education of China and China Postdoctoral Science Foundation.

\section{COMPETING INTERESTS}

The authors declare that they have no competing interests.

\section{REFERENCES}

1. Cervello M, McCubrey JA, Cusimano A, Lampiasi N, Azzolina A, Montalto G. Targeted therapy for hepatocellular carcinoma: novel agents on the horizon. Oncotarget. 2012; 3(3): 236-260.

2. Lee JS, Hong EK. Hericium erinaceus enhances doxorubicin-induced apoptosis in human hepatocellular carcinoma cells. Cancer Lett. 2010; 297(2): 144-154.

3. Llovet JM, Burroughs A, Bruix J. Hepatocellular carcinoma. Lancet. 2003; 362(9399): 1907-1917.

4. Noto A, De Vitis C, Roscilli G, Fattore L, Malpicci D, Marra E, et al. Combination therapy with anti-ErbB3 monoclonal antibodies and EGFR TKIs potently inhibits Non-small Cell Lung Cancer. Oncotarget. 2013; 4 (8): 1253-1265.

5. Llovet JM. Updated treatment approach to hepatocellular carcinoma. J Gastroenterol. 2005; 40 (3): 225-235.

6. Chatterjee K, Zhang J, Honbo N, Karliner JS. Doxorubicin cardiomyopathy. Cardiology 2010; 115 (2): 155-162.

7. Takemura G, Fujiwara H. Doxorubicin-induced cardiomyopathy from the cardiotoxic mechanisms to management. Prog Cardiovasc Dis. 2007; 49 (5): 330-352.

8. Weiss RB. The anthracyclines: will we ever find a better doxorubicin? Semin Oncol. 1992; 19: (6) 670-686.

9. Gewirtz DA. A critical evaluation of the mechanisms of action proposed for the antitumor effects of the anthracycline antibiotics adriamycin and daunorubicin. Biochem Pharmacol. 1999; 57 (7): 727-741.

10. Minotti G, Menna P, Salvatorelli E, Cairo G, Gianni L. Anthracyclines: molecular advances and pharmacologic developments in antitumor activity and cardiotoxicity. Pharmacol Rev. 2004; 56 (2): 185-229.

11. Chen Y, Chen J, Loo A, Jaeger S, Bagdasarian L, Yu J, et al. Targeting HSF1 sensitizes cancer cells to HSP90 inhibition. Oncotarget. 2013; 4 (6): 816-829.

12. Chiarini F, Lonetti A, Teti G, Orsini E, Bressanin D, Cappellini A, et al. A combination of temsirolimus, an allosteric mTOR inhibitor, with clofarabine as a new therapeutic option for patients with acute myeloid leukemia. Oncotarget. 2012; 3 (12): 1615-1628.

13. Posthumadeboer J, van Egmond PW, Helder MN, de Menezes RX, Cleton-Jansen AM, Belien JA, et al. Targeting JNK-interacting-protein-1 (JIP1) sensitises osteosarcoma to doxorubicin. Oncotarget 2012; 3 (10): 1169-1181. 
14. Azmi AS, Banerjee S, Ali S, Wang Z, Bao B, Beck FW, et al. Network modeling of MDM2 inhibitor-oxaliplatin combination reveals biological synergy in wt-p53 solid tumors. Oncotarget. 2011; 2 (5): 378-392.

15. Kruh GD, Goldstein LJ. Doxorubicin and multidrug resistance. Curr Opin Oncol. 1993; 5(6): 1029-1034.

16. Gogas HJ, Kirkwood JM, Sondak VK. Chemotherapy for metastatic melanoma: time for a change? Cancer. 2007; 109(3): 455-464.

17. Schomburg L, Schweizer U, Kohrle J. Selenium and selenoproteins in mammals: extraordinary, essential, enigmatic. Cell Mol Life Sci. 2004; 61(16): 1988-1995.

18. Yan L, Yee JA, Li D, McGuire MH, Graef GL. Dietary supplementation of selenomethionine reduces metastasis of melanoma cells in mice. Anticancer Res. 1999; 19(2A): 1337-1342.

19. Li D, Graef GL, Yee JA, Yan L. Dietary supplementation with high-selenium soy protein reduces pulmonary metastasis of melanoma cells in mice. J Nutr. 2004; 134(6): 1536-1540.

20. Sinha R, El-Bayoumy K. Apoptosis is a critical cellular event in cancer chemoprevention and chemotherapy by selenium compounds. Curr Cancer Drug Targets. 2004; 4(1): $13-28$.

21. Hu H, Jiang C, Ip C, Rustum YM, Lu J. Methylseleninic acid potentiates apoptosis induced by chemotherapeutic drugs in androgen-independent prostate cancer cells. Clin Cancer Res. 2005; 11(6): 2379-2388.

22. Li S, Zhou Y, Wang R, Zhang H, Dong Y, Ip C. Selenium sensitizes MCF-7 breast cancer cells to doxorubicininduced apoptosis through modulation of phospho-Akt and its downstream substrates. Mol Cancer Ther. 2007; 6(3): 1031-1038.

23. Chen T, Wong YS. Selenocystine induces reactive oxygen species-mediated apoptosis in human cancer cells. Biomed Pharmacother. 2009; 63(2): 105-113.

24. Chen T, Zheng W, Wong YS, Yang F. Mitochondriamediated apoptosis in human breast carcinoma MCF-7 cells induced by a novel selenadiazole derivative. Biomed Pharmacother. 2008; 62(2): 77-84.

25. Liu C, Liu Z, Li M, Li X, Wong YS, Ngai SM, et al. Enhancement of auranofin-induced apoptosis in MCF-7 human breast cells by selenocystine, a synergistic inhibitor of thioredoxin reductase. PLoS One. 2013; 8(1): e53945.

26. Gedaly R, Angulo P, Hundley J, Daily MF, Chen C, Koch A, et al. PI-103 and sorafenib inhibit hepatocellular carcinoma cell proliferation by blocking Ras/Raf/MAPK and PI3K/AKT/mTOR pathways. Anticancer Res. 2010; 30(12): 4951-4958.

27. Singh RP, Dhanalakshmi S, Agarwal R. Phytochemicals as cell cycle modulators--a less toxic approach in halting human cancers. Cell Cycle. 2002; 1(3): 156-161.

28. Yamaguchi M, Fujimori-Tonou N, Yoshimura Y, Kishi T, Okamoto H, Masai I. Mutation of DNA primase causes extensive apoptosis of retinal neurons through the activation of DNA damage checkpoint and tumor suppressor p53. Development. 2008; 135(7): 1247-1257.

29. Roos WP, Kaina B. DNA damage-induced apoptosis: From specific DNA lesions to the DNA damage response and apoptosis. Cancer Lett. 2012;332(2):237-248.

30. Norbury CJ, Zhivotovsky B. DNA damage-induced apoptosis. Oncogene. 2004; 23(16): 2797-808.

31. Lopergolo A, Tavecchio M, Lisanti S, Ghosh JC, Dohi T, Faversani A, et al. Chk2 phosphorylation of survivinDeltaEx3 contributes to a DNA damage-sensing checkpoint in cancer. Cancer Res. 2012; 72(13): 3251-3259.

32. Wei D, Li H, Yu J, Sebolt JT, Zhao L, Lawrence TS, et al. Radiosensitization of human pancreatic cancer cells by MLN4924, an investigational NEDD8-activating enzyme inhibitor. Cancer Res. 2012; 72(1): 282-293.

33. Yi YW, Kang HJ, Kim HJ, Kong Y, Brown ML, Bae I. Targeting mutant p53 by a SIRT1 activator YK-3-237 inhibits the proliferation of triple-negative breast cancer cells. Oncotarget. 2013; 4(7): 984-994.

34. Fan C, Chen J, Wang Y, Wong YS, Zhang Y, Zheng W, et al. Selenocystine potentiates cancer cell apoptosis induced by 5 -fluorouracil by triggering reactive oxygen speciesmediated DNA damage and inactivation of the ERK pathway. Free Radic Biol Med. 2013; 65C: 305-316.

35. Li L, Cao W, Zheng W, Fan C, Chen T. Ruthenium complexes containing 2,6-bis(benzimidazolyl)pyridine derivatives induce cancer cell apoptosis by triggering DNA damage-mediated p53 phosphorylation. Dalton Trans. 2012; 41(41): 12766-12772.

36. El-Deiry WS. The role of p53 in chemosensitivity and radiosensitivity. Oncogene. 2003; 22(47): 7486-7495.

37. Pellegata NS, Antoniono RJ, Redpath JL, Stanbridge EJ. DNA damage and p53-mediated cell cycle arrest: a reevaluation. Proc Natl Acad Sci U S A. 1996; 93(26): 15209-15214.

38. McCubrey JA, Steelman LS, Chappell WH, Abrams SL, Montalto G, Cervello M, et al. Mutations and deregulation of Ras/Raf/MEK/ERK and PI3K/PTEN/Akt/mTOR cascades which alter therapy response. Oncotarget. 2012; 3(9): 954-987.

39. Chappell WH, Steelman LS, Long JM, Kempf RC, Abrams SL, Franklin RA, et al. Ras/Raf/MEK/ERK and PI3K/ PTEN/Akt/mTOR inhibitors: rationale and importance to inhibiting these pathways in human health. Oncotarget. 2011; 2(3): 135-164.

40. McCubrey JA, Steelman LS, Chappell WH, Abrams SL, Franklin RA, Montalto G, et al. Ras/Raf/MEK/ERK and PI3K/PTEN/Akt/mTOR cascade inhibitors: how mutations can result in therapy resistance and how to overcome resistance. Oncotarget. 2012; 3(10): 1068-1111.

41. Li XL, Xu G, Chen T, Wong YS, Zhao HL, Fan RR, et al. Phycocyanin protects INS-1E pancreatic beta cells against human islet amyloid polypeptide-induced apoptosis through 
attenuating oxidative stress and modulating JNK and p38 mitogen-activated protein kinase pathways. Int J Biochem Cell Biol. 2009; 41(7): 1526-1535.

42. Zhang H, Chen T, Jiang J, Wong YS, Yang F, Zheng W. Selenium-containing allophycocyanin purified from selenium-enriched Spirulina platensis attenuates AAPHinduced oxidative stress in human erythrocytes through inhibition of ROS generation. J Agric Food Chem. 2011; 59(16): 8683-8690.

43. Tallarida RJ. Drug Synergism: Its Detection and Applications. J Pharmacol Exp Ther 2001; 298(3): 865-872. 